\title{
Gastric emptying and intestinal transit of pancreatic enzyme supplements in cystic fibrosis
}

\author{
C J Taylor, P G Hillel, S Ghosal, M Frier, S Senior, W B Tindale, N Read
}

\begin{abstract}
Objective-To investigate gastric emptying and intestinal transit of pelleted pancreatin in relation to food boluses. Methods-Dual isotope scintigraphy combined with breath hydrogen sampling was used to track the concurrent gastric emptying and intestinal transit of ${ }^{11}$ indium labelled microspheres and $a^{99 \mathrm{~m}}$ technetium labelled tin colloid test meal. Twelve pancreatic insufficient cystic fibrosis patients aged 5 to 38 years performed the study.

Results-50\% gastric emptying times showed patient to patient variation. The mean discrepancy in $\mathbf{5 0 \%}$ gastric emptying times between the two labels was $>67$ minutes. Mean small bowel transit time for the food bolus was prolonged at $\mathbf{3 . 6}$ minutes. A significant correlation was seen between weight standard deviation score and $50 \%$ emptying time for pancrea$\operatorname{tin}(r=+0.73)$.

Conclusion-Gastric mixing of food and pancreatin may be limited by rapid emptying of microspheres. Patients with high dosage requirements could benefit from changing the pattern of their pancreatin supplementation.

(Arch Dis Child 1999;80:149-152)
\end{abstract}

Keywords: pancreatin; cystic fibrosis; isotopes

Department of Paediatrics, University of Sheffield, Sheffield

S10 2TN, UK

C J Taylor

S Ghosal

Department of Medical Physics and Clinical Engineering, University of Sheffield P G Hillel

S Senior

W B Tindale

Centre for Human Nutrition, University of Sheffield

N Read

Queen's Medical Centre, Nottingham NG7 2UH, UK

M Frier

Correspondence to: Professor C J Taylor, Department of Paediatrics, Sheffield Children's Hospital, Sheffield S10 2TH, UK.

Accepted 10 August 1998

malabsorption. This is usually perceived secondary to exocrine pancreatic insufficiency;
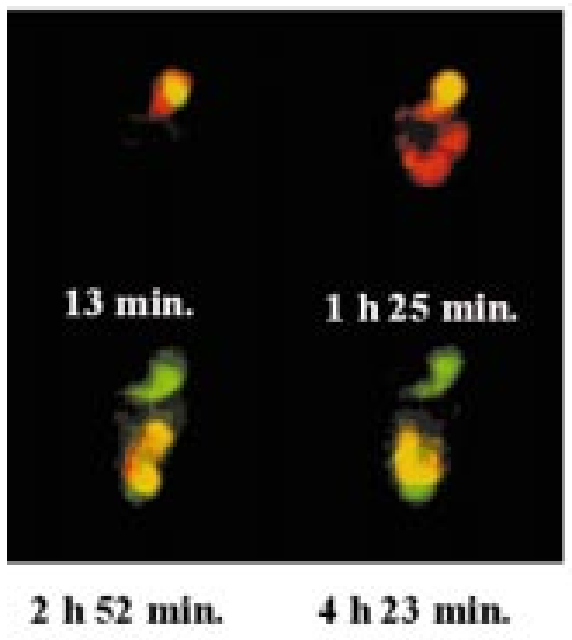

however, deficient pancreatic enzyme secretion is only one of several abnormalities that combine to produce steatorrhoea and azotorrhoea. Nevertheless, malabsorption is traditionally dealt with by titrating pancreatin dosage against symptoms. Most patients with $\mathrm{CF}$ achieve adequate weight gain and bowel control with modest intakes of pancreatin (< $10000 \mathrm{U}$ lipase/kg/day); others, despite huge doses, remain symptomatic. Most physicians accept the need for high dose treatment in this minority of patients; however, the association of fibrosis and stricturing in the proximal colon and high dose pancreatin supplementation $^{1}$ has led to a reappraisal of enzyme dosage and the factors that influence pancreatin function.

Previously, we have shown that an inappropriately acidic proximal intestine may delay enzyme release and inhibit activity. ${ }^{2}$ Therefore, it is likely that the bioavailability of some pancreatin preparations might be improved with $\mathrm{H}_{2}$ blockers ${ }^{3}$; however, oral antacid treatment used in conjunction with microsphere preparations has produced inconsistent effects. ${ }^{45}$ Thus, other factors such as the kinetics of gastric emptying and release characteristics of the enzyme preparation ${ }^{6}$ may be more pertinent to the efficacy of current pancreatin treatment. We have devised an isotopic technique to investigate possible mismatch between gastric emptying and intestinal transit of the food bolus and granulated pancreatin preparations under physiological conditions in vivo using a simulated test meal.

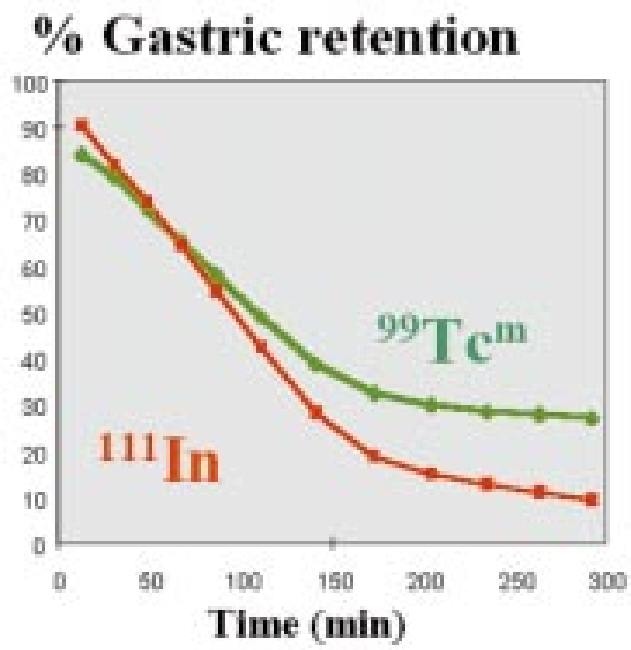

Figure 1 Example of gastric emptying study from a single patient given a mixture of ${ }^{99}{ }^{2 m}$ anionic resin beads and the ${ }^{111}$ In cationic resin beads encapsulated in gelatine capsules. It can be seen that gastric emptying of the two resins is not synchronised, posing questions as to the validity of using the ${ }^{111}$ In resin beads to simulate the enzyme pellets. 

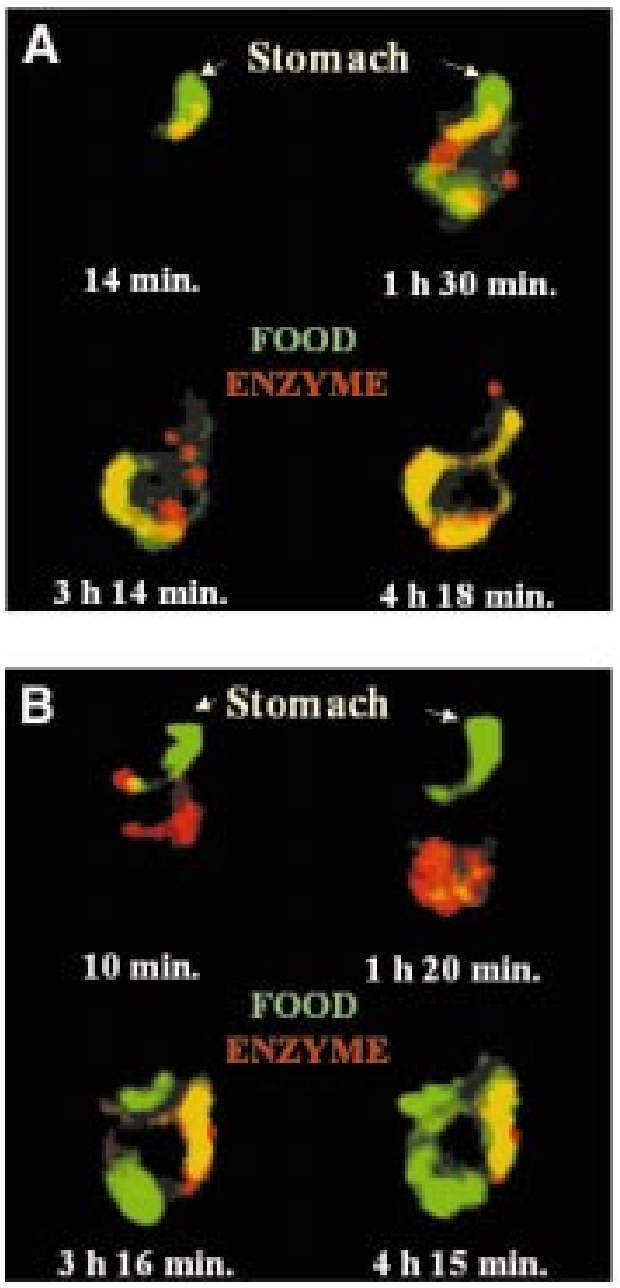
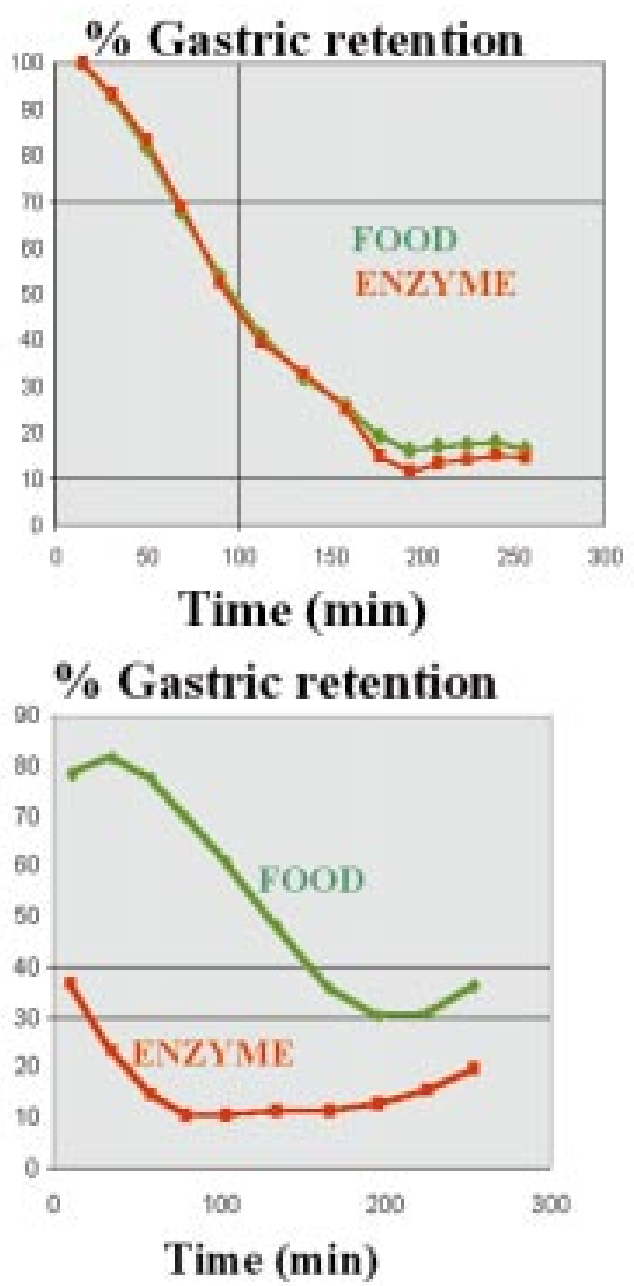

Figure 2 Scintigraphs and gastric emptying curves from two subjects showing examples of $(A)$ good and (B) poor correlations between the ${ }^{99} T c^{m}$ labelled test meal (green) and the ${ }^{11 i}$ In labelled pancreatin (red).

\section{Methods}

Dual isotope imaging combined with breath hydrogen sampling was used to follow the synchronous transit of food and enzyme pellets from the stomach to the proximal colon. Initially, a ${ }^{99 \mathrm{~m}}$ technetium $\left({ }^{99} \mathrm{Tc}^{\mathrm{m}}\right)$ labelled test meal (resin density, $1.08 \mathrm{~g} / \mathrm{ml}$; particle size, $0.15-0.3 \mathrm{~mm})$, together with ${ }^{111}$ indium $\left({ }^{111} \mathrm{In}\right)$ labelled cationic resin beads (density, $0.77 \mathrm{~g} /$ $\mathrm{ml}$; particle size, $0.3-1.2 \mathrm{~mm}$ ), to simulate pancreatin microspheres, was used as described previously. ${ }^{7-9}$ However, data from our first five patients suggested that the technetium was delabelling and entering the bloodstream as free pertechnetate. Furthermore, preliminary work with the indium labelled beads raised doubts about this technique for simulating enzyme transit, despite the similarity in densities and particle size (fig 1). In view of these inconsistencies, an improved labelling protocol was developed, enabling the pancake test meal to be labelled directly with ${ }^{99} \mathrm{Tc}^{\mathrm{m}}$ tin colloid and the pancreatin pellets (mean diameter, $<1.2 \mathrm{~mm}$ ) directly with ${ }^{111}$ In chloride. ${ }^{10}$

Twelve patients with CF aged 5 to 38 years were studied using this improved protocol. All were pancreatic insufficient and receiving the currently recommended lipase/protease intake for each $\mathrm{kg}$ of bodyweight. Patients with a his- tory of bowel surgery for meconium ileus were excluded, as were patients with existing colonic strictures. Baked beans acted as the hydrogen source. ${ }^{11}$ Data were analysed using the Wilcoxon matched pair signed rank test. The study was approved by the local research ethics committee and ARSAC.

After an overnight fast, each patient was given the standard pancake and baked bean test meal (400 kcal), together with four enzyme capsules (32 $000 \mathrm{U}$ lipase). Patients were instructed to take all the pancreatin with a drink of dilute juice immediately before the meal. Small bowel transit was established using breath hydrogen sampling, with a rise in breath hydrogen excretion (>20 ppm) indicating the head of the meal entering the colon. ${ }^{12}$ Lunch consisting of sandwiches, crisps, and a sugar free drink was given three to four hours after the breakfast. Gamma camera recording was carried out every 15 minutes until gastric emptying had taken place and then every 30 minutes until the end of the study (300-360 minutes).

\section{Results}

There was considerable variation in gastric emptying and intestinal transit for food and pancreatin microspheres in individual patients, with enzyme pellets generally emptying from 
Table 1 Patients studied with new labelling technique

\begin{tabular}{|c|c|c|c|c|c|}
\hline \multirow[b]{2}{*}{ Patient } & \multirow{2}{*}{$\begin{array}{l}\text { Weight } \\
Z \text { score }\end{array}$} & \multirow{2}{*}{$\begin{array}{l}\text { Small gut } \\
\text { transit time } \\
\text { (hours) }\end{array}$} & \multicolumn{2}{|c|}{$\begin{array}{l}50 \% \text { gastric emptying time } \\
\text { (minutes) }\end{array}$} & \multirow{2}{*}{$\begin{array}{l}\text { Difference in gastric } \\
\text { emptying (minutes) }\end{array}$} \\
\hline & & & ${ }^{99} \mathrm{Tc}^{m}$ (food) & ${ }^{111}$ In (enzyme) & \\
\hline 1 & +0.5 & 3.2 & 73 & 105 & 32 \\
\hline 2 & -4.0 & 3.5 & 131 & 10 & 121 \\
\hline 3 & +1.2 & 5.5 & 200 & 89 & 111 \\
\hline 4 & -3.0 & 3.8 & 115 & 10 & $>105$ \\
\hline 5 & -1.0 & 2.4 & 97 & 94 & 3 \\
\hline 6 & -2.2 & 3.0 & 109 & 50 & 59 \\
\hline 7 & +1.6 & 3.0 & 86 & 161 & 75 \\
\hline 8 & +2.7 & 3.4 & 141 & 182 & 41 \\
\hline 9 & +0.5 & 4.5 & 72 & 104 & 32 \\
\hline 10 & +0.19 & 3.25 & 98 & 127 & 29 \\
\hline 11 & -0.16 & 4.8 & 78 & $<10$ & $>68$ \\
\hline 12 & -0.96 & 3.3 & 41 & 170 & 129 \\
\hline Mean & -0.37 & 3.6 & 103 & $<93$ & $>67$ \\
\hline
\end{tabular}

the stomach more rapidly than food. Examples of good and poor correlations are shown in fig $2 \mathrm{~A}$ and $\mathrm{B}$. Individual small bowel transit times, $50 \%$ gastric emptying times, and weight $\mathrm{Z}$ scores for the 12 patients studied using the modified protocol are given in table 1 .

The mean (SE) $50 \%$ gastric emptying time for the ${ }^{99} \mathrm{Tc}^{\mathrm{m}}$ labelled test meal was 103.4 (11.8) minutes, and for the ${ }^{111} \mathrm{In}$ labelled pancreatin it was 92.7 (17.9) minutes. Because digestion within the intestine requires adequate mixing of food and pancreatin, differences in paired emptying times were considered, irrespective of which label emptied more quickly. There was a mean discrepancy between the paired emptying times of 67 minutes. A significant correlation $(p<0.01)$ was seen between weight SD score and $50 \%$ emptying time for pancreatin $(r=+0.73$; fig 3$)$. There was also more variation in paired emptying times in patients with suboptimal nutritional status as defined by a negative weight SD score (range, 3-129 minutes) compared with patients showing good nutritional status.

Small bowel transit for the food, measured using breath hydrogen excretion, was derived for the combined group of 17 patients because delabelling was thought unlikely to influence this measurement. Transit times varied from 2.4 hours to $>6$ hours, the limit of the study, in two patients (mean, 3.6 hours). Labelled pancreatin appeared in the terminal ileum/ colon by two hours in most patients, with obvious "hot spots" of isolated pancreatin evident in the right lower quadrant in three patients.

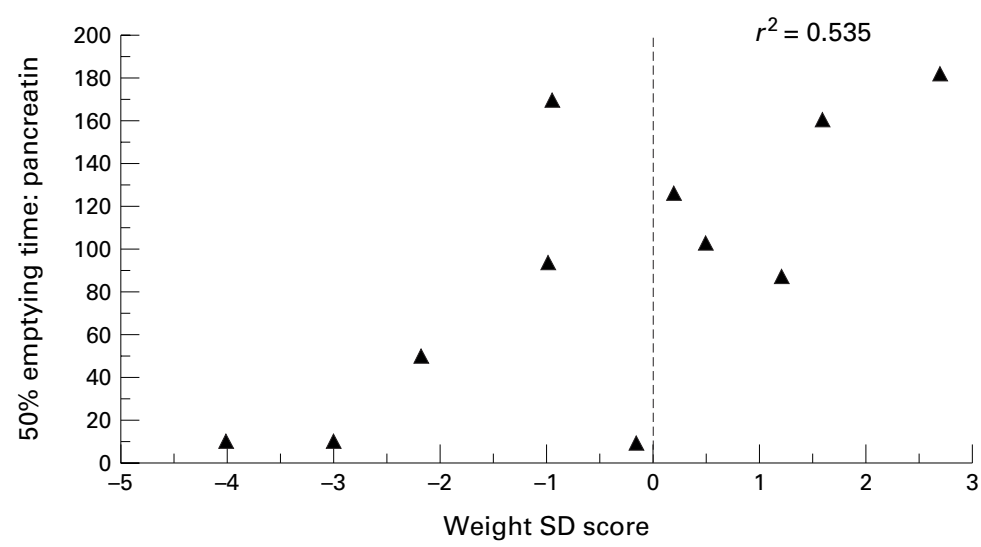

Figure 3 Correlation between weight SD score and 50\% gastric emptying times for pancreatin pellets.

\section{Discussion}

We have illustrated clearly, using a synchronous recording and dual labelling technique, mismatch in gastric emptying and intestinal transit between enzyme pellets and food boluses. This non-synchronous transit could be the result of poor mixing of chyme and pancreatin in the stomach, with partitioning of the pancreatin with the liquid phase of the meal, which empties more rapidly than the solid phase. ${ }^{13}$ Unfortunately, there are no similar published data in children with $\mathrm{CF}$ to compare our results with. However, comparative data on gastric emptying for food and pancreatin are available from studies in healthy adults. ${ }^{14}$ Meyer et al, using ${ }^{99} \mathrm{Tc}^{\mathrm{m}}$ labelled liver and ${ }^{113 \mathrm{~m}}$ In labelled polyamide spheres suggested that gastric emptying of food and $1.6 \mathrm{~mm}$ spheres show interindividual variation in delivery of pancreatin to the proximal intestine. ${ }^{8}$ In addition, Delchier et al found duodenal lipase recovery rates ranging from $3 \%$ to $80 \%$ in adults with exocrine pancreatic insufficiency. ${ }^{15}$

We were also able to confirm previous reports of slow small bowel transit in patients with $\mathrm{CF},{ }^{16}{ }^{17}$ although intestinal transit measurements performed in this way can only be approximate. Breath hydrogen testing, used to track the test meal, provides a useful index of small bowel transit for the head of the meal, but does not reflect the time taken for all the meal to enter the colon. Thus, any differences in transit between food and pancreatin identified using this methodology are likely to be underestimated. Acquisitions over the right iliac fossa were used to identify the presence of label in the terminal ileum and proximal colon. While this is partly subjective, tracking of activity in individual patients before and after the isotope reached the right iliac fossa helped confirm the location. Breath hydrogen analysis also aided identification of the caecum. In three of 12 patients, enzyme hot spots were visualised in the colon before the food bolus reached this area.

Previously, we have shown that in $\mathrm{CF}$, defective $\mathrm{Cl}^{-} / \mathrm{HCO}_{3}{ }^{-}$exchange in the pancreatic ducts $^{18}{ }^{19}$ results in pancreatic secretions with insufficient $\mathrm{HCO}_{3}{ }^{-}$to neutralise gastric acid. ${ }^{2}$ The resulting duodenal hyperacidity is sufficient to delay the release of microsphere pancreatic enzyme preparations (pancreatic enzymes are not released from enteric coated microspheres below $\mathrm{pH}$ 5.5) or irreversibly denature any enzyme released from the enteric coating. We have now shown that there is considerable individual variation in mixing, gastric emptying, and intestinal transit of food and pancreatin, and have demonstrated that this mismatch is associated with poor weight gain. Moreover, as transit slows and $\mathrm{pH}$ rises in the terminal ileum, free pancreatin is likely to be released into the caecum, and this could be relevant to the fibrosing colonopathy reported recently in some patients with CF.

Our study demonstrates the multifactorial nature of malabsorption in $\mathrm{CF}$ and goes some way to explain why many patients with CF require more than the estimated $30000 \mathrm{U}$ 
lipase activity to digest the fat content of a normal meal. Further studies will be required to determine the release pattern of enteric coated pancreatin in the intestine. Information on $\mathrm{pH}$ profiles throughout the small bowel would be helpful in this respect. Patients should spread their pancreatin dosage throughout the meal to limit partitioning and to optimise mixing. Enteric coated enzyme microspheres/mini-tablet preparations may need to incorporate dispersing agents to facilitate even mixing with food.

Dr Ghosal was funded by the Cystic Fibrosis Trust. We thank Solvay Health Care for their help in the development of this project and the Cystic Fibrosis Trust who supported the study.

1 Smith RL, van Velzen D, Smyth AR, Lloyd DA, Heaf DP. Strictures of ascending colon in cystic fibrosis and high-strength pancreatic enzymes. Lancet 1994;343:85-6.

2 Barraclough M, Taylor CJ. 24 hour ambulatory gastric and duodenal $\mathrm{pH}$ profiles in cystic fibrosis: effect of duodenal hyperacidity. F Pediatr Gastroenterol Nutr 1996;23:45-50.

3 Cox RL, Isenberg JN, Oshen AB, Dooley RR. The effect of cimetidine on maldigestion in cystic fibrosis. I Pediatr cimetidine on

4 Nassif EG, Younoszai MK, Weinberger MM, Nassif CM. Comparative effects of antacids, enteric coating and bile salts on the efficacy of oral pancreatic enzyme therapy in cystic fibrosis. F Pediatr 1981;98:320-3.

5 Gow R, Bradbear R, Francis P, Shepherd R. Comparative study of varying regimens to improve steatorrhoea and creatorrhoea in cystic fibrosis: effectiveness of an entericcoated preparation with and without antacids and cimetidine. Lancet 1981;14:1071-4.

6 Guarner L, Rodriguez R, Guarner F, Malagelada J-R. Fate of oral enzymes in pancreatic insufficiency. Gut 1993;34: 708-12.

7 Bechgaard H, Christensen FN, Davis SS, et al. Gastrointestinal transit of pellet systems in ileostomy subjects and the effect of density. F Pharmac Pharmacol 1985;37:718-21.
8 Meyer JH, Elashoff J, Porter-Fink V, Dressman J, Amidon GL Human postprandial gastric emptying of $1-3$ milliGL. Human postprandial gastric emptying of 1

9 Bechgaard H, Ladeford K. Distribution of pellets in the gastrointestinal tract. The influence of transit time exerted by the density or diameter of pellets. F Pharm Pharmacol 1978;30:690-2.

10 Hillel PG, Tindale WB, Taylor CJ, Frier M, Senior S, Ghosal $S$. The use of dual-isotope imaging to compare the gastrointestinal transit of food and pancreatic enzyme pellets in cystic fibrosis patients. Nucl Med Commun 1998;19: $761-9$.

11 Read NW, Miles CA, Fisher D, et al. Transit of a meal through the stomach, small intestine and colon in normal subjects and its role in the pathogenesis of diarrhoea. Gastroenterology 1980;79:1276-82.

12 Read NW. Measurement of small bowel transit in humans. In: Kamm MA, Lennard Jones JE, eds. Gastrointestinal transit pathophysiology and pharmacology. Wrightson Biomedical Publishing, 1991.

13 Heading RC, Tothill P, Mcloughlin GP, Shearman DJC. Gastric emptying rate measurement in man: a double isotope scanning technique for simultaneous study of liquid and solid components of a meal. Gastroenterology 1976;71:45-50.

14 Bruno MJ, Borm JJJ, van Royen EA, et al. Gastric transit profile of a multi-unit pharmaceutical dose preparation in relation to a solid test meal in healthy volunteers: assesssment by location-time analysis. In: Bruno MJ. Amsterdam: PhD thesis, 1995.

15 Delchier JC, Vidon N St, Marc-Girardin MF, et al. Fate of orally ingested enzymes in pancreatic insufficiency: comparison of two pancreatic enzyme preparations. Aliment Pharmacol Ther 1991;5:365-78.

16 Murphy MS, Brunetto AL, Pearson AD, et al. Gut hormones and gastrointestinal motility in children with hormones and gastrointestinal motility in
cystic fibrosis. Dig Dis Sci 1992;37:187-92.

17 Bali A, Stableforth DE, Asquith P. Prolonged smallintestinal transit time in cystic fibrosis. BMF Clin Res Ed 1983;287:1011-3

18 Gillespie JI, Hedley C, Greenwell JR, Argent BE. Chloridebicarbonate exchange in isolated rat pancreatic acini. Quarterly fournal of Experimental Physiology 1989;74:88395.

19 Gray MA, Plant S, Argent BE. cAMP-regulated whole cell chloride currents in pancreatic duct cells. Am $\mathcal{F}$ Physiol 1993;264:C591-602. 